a thousand poriodicals. Comments by the abstractors are printed inside square brackets, so that there will be no confusion between the views of the abstractor and those of the authors of the article abstracted.

The type chosen for the new journals is attractive and clear, and they are so bound that they are pleasant and convenient to use. They form a valuable supplement to the excellent epitomes of British medical literature published in the British Medical Bulletin, which was born in 1940 in the editorial department of the British Medical Association as a medical information service to provide, in collaboration with the Ministry of Information, foreign medical journals with surveys of current British medical literature. Later, this service was taken over by the British Council and became, under the able editorship of Dr. Howard-Jones, the British Medical Bulletin, which is now an essential feature of medical literature. Medical men all over the world now have, therefore, an information service which should keep them well informed of every important development.

\section{British Standard Specification for Cable Insulation}

A 1946 edition of the well-known British Standard No. 7, the first edition of which appeared in 1904, and which deals with rubber-insulated cables and flexible cords for electric power and lighting, has recently been issued. The main specification, together with a supplement on the use of polyvinyl chloride compounds as an alternative to vulcanized rubber, is published as a single volume (B.S.7 ; 1946. British Standards Institution, Publications Department, 28 Victoria Street, London, S.W.1. 3s. 6d., post paid) and an amendment, entitled "Transitory Relaxations", is issued separately in the form of a leaflet (Ref. PD 540). War-time conditions hastened the introduction of polyvinyl chloride insulated cables, and this necessitated several modifications to the original specification. The 1946 edition, while retaining in substance all the usual features, makes allowance for the change-over to peace-time conditions. Some of the modifications referred to above are retained as permanent revisions to the specification, others are retained only temporarily, to be dropped eventually, while others have been entirely cancelled. The specification is divided into three sections : the first, of a general nature, defining terms, sizes, etc., used later in the specification; the second, dealing with the construction of the different types of cables and cords; and the third, with tests for thickness of insulation and sheath, voltage, insulation resistance, spark testing, tinning and armouring. The numerous tables with which the specification is provided make the publication an extremely useful one for all users and manufacturers of electrical cables and cords.

\section{Durban Museum and Art Gallery}

Although the annual report of the Durban Museum and Art Gallery for the year ended July 31, 1945, shows their satisfactory maintenance as cultural and educational centres, it points out the need for extensions if these institutions are to function in a manner adequate to the future needs of a city growing in both size and importance. A new building has been embodied in $\mathbf{a}$ post-war development scheme, and it is now recommended that this be erected as soon as circumstances permit. Schools continued to make good use of the Museum services during the year. Eighty-nine gallery talks-many of which were augmented by lantern-slide or film shows -were delivered to visiting classes, and the showing of instructional films relating to subjects lying within the scope of the Museum was a regular weekly feature. An interesting departure from the usual type of film shown in museums was one demonstrating the activities of the Durban municipal departments.

\section{History and Comparative Study of Religion}

AN effort is being made to establish in Cambridge a photographic record for use in illustrating the history and comparative study of religions. Any persons, especially those returning from the Services or from the mission field, who may have photographic prints of religious buildings or ceremonies (whether Christian or non-Christian), are invited to send spare copies for this collection. Any contributions will be filed and preserved, with the names of the donors duly recorded. Communications should be sent to the voluntary curator of the record, the Rev. Dr. Bouquet, Gilling House, Madingley Road, Cambridge. It is also desired to register the whereabouts of cinematograph films dealing with the same subjects, especially if in private hands.

\section{Summer School in Social Biology (Switzerland)}

THE British Social Hygiene Council proposes holding a summer school on "Social Biology: its International Aspects", in Switzerland during the last fortnight in August. It is proposed to devote one week to study and the second week to visits, expeditions and recreation. The School is intended for teachers and social workers, and others interested in social biology from Britain, but it is hoped that there will also be students from other countries. Lectures will be in English. The estimated cost, including travel, board and tuition, will be between $£ 25$ and $£ 30$. Further information can be obtained from the Secretary, British Social Hygiene Council, Tavistock House North, Tavistock Square, London, W.C.I.

\section{Announcements}

Mr. S. S. CARLISLE, a graduate of Queen's University, Belfast, has been appointed head of the Instrument Section of the British Iron and Steel Research Association, in succession to Mr. W. C. Fahie, who is taking up an appointment in the Ministry of Defence. $\mathrm{Mr}$. Carlisle joined the Association in October 1946, following four years' service in the Experimental Department, H.M.S. Excellent, Portsmouth, on the staff of the Director of Scientific Research, Admiralty, where he was largely responsible for the design and development of certain special recording instruments and electro-mechanical control systems associated with modern gunnery and radar techniques.

ONE of the activities of the Viking Fund (14 East 71 st Street, New York) is the publication, in conjunction with its summer seminar in physical anthropology, of a "Yearbook of Physical Anthropology", which consists, in the main, of reproduction in full of a score of important papers appearing during the year. The yearbook is distributed free of charge to members of the American Association of Physical Anthropologists and to other interested persons. The second issue (for 1946) is now in preparation, and the editor, Dr. Gabriel Lasker, would welcome reprints and references to material which might be considered for inclusion. 